\title{
Racismo Ambiental e a Pesca Artesanal: o caso da Ilha de Deus, Pernambuco
}

\author{
Environmental Racism and Artisanal Fishing: the case of 'Ilha de Deus', Pernambuco, Brazil
}

\author{
Ivo Raposo Gonçalves Cidreira-Neto ${ }^{1}$ \\ Gilberto Gonçalves Rodrigues ${ }^{2}$
}

\section{Resumo}

O processo de urbanização no Brasil possibilitou o surgimento de locais que não receberam a atenção pública necessária, sendo conhecidas como "cidades informais", caracterizadas também pelo descaso ambiental. Com base nesta problemática, o objetivo desse trabalho é compreender como o racismo ambiental surge e se instala nos grupos pesqueiros, trazendo como estudo de caso a comunidade da Ilha de Deus, situada na Cidade do Recife, Estado de Pernambuco. Contextualiza-se neste estudo que devido a relação Homem \& Natureza ter base utilitarista, voltada para o acúmulo de capital, teve-se a criação de políticas ambientais como instrumento legal de defesa do meio ambiente, assegurando a continuidade dos recursos naturais. Esse cenário fundamentado no modelo hegemônico do desenvolvimento resultou na segregação do direito ao território ecologicamente saudável, no qual as populações ricas ficam alocadas nas cidades, com direitos básicos garantidos, enquanto os pobres são alocados às margens da sociedade, em locais com elevado grau de poluição e descaso ambiental. As comunidades artesanais pesqueiras frequentemente são exemplos de exclusão, devido a diversos fatores como o trabalho na lama dos manguezais. A Ilha de Deus, como estudo de caso típico das inúmeras comunidades pesqueiras do Recife, é um território de pesca, onde os comunitários passam diariamente por casos de racismo ambiental, tornando-se um exemplo de resistência, onde a comunidade não se deixa levar pelos padrões capitalistas, lutando pelo direito à pesca.

Palavras-chave: Injustiça ambiental. Direito Ambiental. Comunidade pesqueira.

\section{Abstract}

The Brazilian urbanization process led the emergence of places that did not receive decent public attention, being known as "informal cities", also characterized by the environmental neglect. Based on these problems, the objective of this study is to understand how environmental racism arises and installs in fishing groups, bringing as a case study the community of 'Ilha de Deus', located in the City of Recife, Pernambuco State, Brazil. We argue that the relation between man and nature has a utilitarian base, focused on the accumulation of capital. Environmental policies have been created as a legal instrument to defend the environment, ensuring the continuity of natural resources. This scenario, based on the hegemonic model of development, has resulted in the segregation of the right to get an ecologically healthy territory, where rich populations live in the cities with basic rights guaranteed, while the poor are forced to the outskirts, in places with high levels of pollution and environmental neglect. Artisanal fishing communities are often examples of exclusion due to various factors such as working in the mangrove mud. Ilha de Deus is a case study typical of the many fishing communities in Recife. It is a fishing territory, where community members face daily environmental cases of racism, becoming example of resistance. The community is not subjugated by capitalist standards and struggles for the right to fishing.

Keywords: Environmental injustice. Environmental Law. Fishing Community.

\footnotetext{
${ }^{1}$ Mestrando em Desenvolvimento e Meio Ambiente na Universidade Federal de Pernambuco (PRODEMA/UFPE). Email: ivo.raposo@hotmail.com

${ }^{2}$ Professor do Programa de Pós-Graduação em Desenvolvimento e Meio Ambiente Federal (PRODEMA/UFPE). E-mail: gilbertorodrigues.ufpe@gmail.com
} 


\section{Introdução}

A relação ser humano e natureza é algo complexo, construída a partir de fatores sociais como crenças, política e economia, acompanhando o próprio desenvolvimento da sociedade, passando por construções místicas até utilitaristas (DUARTE, 1986). Nos tempos atuais têm-se um aumento no processo de urbanização, ampliando as cidades com suas regiões metropolitanas, vendendo uma ideia de padrão de vida pouco alcançado pela sociedade em geral, sendo restrita apenas a uma pequena parcela da população. Como resultado do crescimento das cidades, tem o surgimento das favelas e bairros periféricos, configurados por serem locais de baixas condições de moradia, que influencia diretamente na qualidade de vida das populações ali presentes (JACOBI, 2006).

O processo de urbanização resultou em uma dualidade, sendo de um lado a cidade formal, concentrando maior parte dos investimentos públicos e do outro lado a cidade informal, caracterizada pela quantidade de problemas ambientais e pelo não investimento, o que resulta na marginalização das populações residentes nessa área (GROSTEIN, 2001). A autora comenta, ainda, que as áreas informais são embebidas na precariedade e ilegalidade, resultando em locais sem a atenção urbanística necessária. Os locais sem essa devida atenção urbanística sofrem com o descaso ambiental, agravando o sentimento de exclusão.

Dessa forma, o presente artigo surge da necessidade de compreender como o racismo ambiental chega e se instala nos grupos pesqueiros, trazendo como estudo de caso a comunidade da Ilha de Deus, território pesqueiro estabelecido desde o surgimento da Cidade do Recife, Pernambuco, caracterizado por pescadoras e pescadores, com a principal atividade socioeconômica o processamento do sururu e a criação de camarões.

\section{Meio ambiente a partir de esferas sociais}

A política ambiental no Brasil começou a ser implementada a partir do desenvolvimento industrial, iniciado na década de 1930, assim como do surgimento do movimento internacional ambientalista (PECCATIELLO, 2011). Porém, ainda no período colonial, já se tem registros de meios legais para a proteção de bens naturais para a Coroa, como foi instituída na regulamentação da extração do Pau Brasil em 1605, devido a sua imensa exploração (WAINER, 1993). Nos dias atuais, a legislação ambiental nacional é robusta, contando com leis que servem de exemplo internacional, mas que devido a uma carência de uma gestão pública comprometida, acabam não assegurando a sua 
execução. Contudo, o olhar para o meio ambiente, a partir dessas esferas construídas socialmente, demonstra a preocupação com a proteção ambiental, mas que na prática acaba falhando e/ou exaurindo uma discussão mais pertinente.

O meio ambiente, o ser humano, a natureza, o natural e as relações que existem na Terra não são de fácil explicação, visto que os elementos são baseados na sua própria complexidade, sendo analisados a partir de entendimentos sociais construídos com a práxis individual. Como forma de entender o que vem a ser meio ambiente, usamos como base o que é instituído pela Constituição Federal (CF) de 1988, mais precisamente no Capítulo VI, Artigo 225 "Todos têm direito ao meio ambiente ecologicamente equilibrado, bem de uso comum do povo e essencial à sadia qualidade de vida, impondo-se ao Poder Público e à coletividade o dever de defendê-lo e preservá-lo para as presentes e futuras gerações".

Além do exposto pela CF, outras diretrizes foram instituídas, como a Política Nacional do Meio Ambiente (PNMA), Lei № 6.938 de agosto de 1981, trazendo como elemento principal a estabilidade e preservação ambiental, com o objetivo de promover o desenvolvimento socioeconômico. Já no seu $3^{\circ}$ artigo vem a definição do conceito de meio ambiente, sendo "o conjunto de condições, leis, influências e interações de ordem física, química e biológica, que permite, abriga e rege a vida em todas as suas formas", assim como a definição da degradação da qualidade ambiental "alteração adversa das características do meio ambiente".

Como forma de mitigar os impactos gerados pelo uso e ocupação desorganizada do meio ambiente, existe uma vasta legislação que, diretamente ou indiretamente, apresentam como finalidade a proteção ambiental, como a Lei No $9.433 / 1997$ (que estabelece a Política Nacional de Recursos Hídricos), a Lei No 9.605/1998 (que estabelece a Lei de Crimes Ambientais), a Lei No 9.795/999 (que estabelece a Política Nacional de Educação Ambiental), e a Lei N ${ }^{\circ} 9.985 / 2000$ e o Decreto $\mathrm{N}^{0} 4.340$ de 2002 e 5.746 de 2006 (que estabelecem o Sistema Nacional de Unidades de Conservação), dentre outros. Como forma de avaliar a potencialidade de obras e empreendimentos com relação aos impactos ambientais, é instituído pelo PNMA, através da Resolução do Conselho Nacional do Meio Ambiente $N^{\circ}$ 01/1986, o Estudo de Impacto Ambiental (EIA), que utiliza diversas técnicas e áreas do conhecimento para realizar um estudo detalhado sobre as possíveis implicações do empreendimento e seus danos ambientais. Como resultado, tem-se o Relatório de Impacto Ambiental (RIMA), que traz as conclusões do EIA, servindo como base para a aprovação do projeto e/ou cancelamento de projetos já iniciados. Esses estudos são realizados por diversas instituições e avaliados pelos órgãos ambientais competentes como o Instituto Brasileiro do Meio Ambiente e dos Recursos Naturais Renováveis (IBAMA), ou por órgãos estaduais, como a Agência Estadual do Meio Ambiente do Estado de 
Pernambuco (CPRH), Instituto Estadual do Ambiente do Rio de Janeiro (INEA), Companhia Ambiental do Estado de São Paulo (CETESB) e a Fundação Estadual de Proteção Ambiental Henrique Luiz Roessler do Rio Grande do Sul (FEPAM).

Além das legislações citadas, existem as que podem ser utilizadas como subsídio para a própria degradação ambiental, quando utilizadas de forma contrária ao seu princípio, como pode ocorrer com o Decreto n ${ }^{\circ}$ 6.848/2009 (que trata da compensação ambiental), que utiliza o EIA/RIMA, analisando os impactos ambientais para que os mesmos possam ser compensados em outras áreas.

No conceito legal, lê-se dentro das normativas da política brasileira, que o meio ambiente é trabalhado a partir de esferas que não incluem o social como elemento natural, no qual a natureza serve como bens passíveis a utilização - recursos naturais. A CF traz que todos têm direito a um ambiente ecologicamente equilibrado, mas essa passagem não remete as condições sociais, mesmo que o equilíbrio da natureza seja nutrido a partir de um equilíbrio social.

Partindo para reflexões, de como o ser humano percebe e interage com a natureza, Branco (1995) traz alguns questionamentos acerca das relações filosófico-sociais existentes em condições de equilíbrio social:

\begin{abstract}
A questão essencial gira em torno do homem/natureza como relação de integração, de simples complementaridade, de estreita dependência ou de domínio absoluto. O homem pertence à natureza? Pertenceu algum dia? Pertencerá no futuro? Em cada caso, quais as condições básicas para que isso se realize? Qual o modelo que mais se coaduna com a relação real homem/natureza: o homem como seu participante; o homem como simples beneficiário natural; o homem como seu dependente? Poderse-ia propor um modelo ideal e futuro de um entrosamento de feição tecnológica (e não como fruto de seleção natural) entre o homem e a natureza? (BRANCO, 1995, p.217).
\end{abstract}

A forma como o ser humano trata o meio ambiente resulta em largas escalas de degradação ambiental, e nesse caso, pode-se atribuir inclusive a degradação social, que são impulsionados pelas relações desenvolvidas ao longo dos anos entre o ser humano e a natureza (CIDREIRA-NETO; RODRIGUES, 2017). Dessa forma, a degradação ambiental pode ser analisada a partir de marcadores históricos, como por exemplo, o período colonial (supressão de matéria prima) e a inserção do capitalismo (supressão para a venda e acumulação de capital). A própria conservação da biodiversidade deve ser analisada de forma integrada entre os aspectos sociais, ecológicos, biológicos e econômicos, visto que estes estão em constante interação, assim como entender as necessidades humanas, conciliando o uso dos bens comuns com estratégias de manejo e conservação (SILVA; ALBUQUERQUE; AMARAL, 2017). 
A formação e consolidação do uso da natureza no Brasil foi e é nutrida de forma exploratória, onde se predomina o poder monetário de grandes instituições do ramo empresarial/industrial, que promovem destruição, escravidão e exclusão como forma de promover o acúmulo de capital. A partir dessa visão, as injustiças ambientais tornaram-se evidentes, assim como o próprio racismo ambiental.

\section{(In) justiça ambiental e o Racismo Ambiental}

Justiça ambiental é um termo simples, utilizado para prevenir um problema complexo. Inicialmente a palavra justiça, segundo o dicionário Aurélio, é a prática e exercício do que é de direito, dessa forma justiça ambiental é o poder de garantir um ambiente ecologicamente saudável, conforme o explicitado na CF. Herculano (2008) também define justiça ambiental como:

(...) conjunto de princípios que asseguram que nenhum grupo de pessoas, sejam grupos étnicos, raciais ou de classe, suporte uma parcela desproporcional das consequências ambientais negativas de operações econômicas, de políticas e programas federais, estaduais e locais, bem como resultantes da ausência ou omissão de tais políticas (HERCULANO, 2008, p. 2).

Partindo dessas definições, entende-se por injustiça ambiental a negligência desses direitos, locando os grupos marginalizados socialmente em locais desfavorecidos de estrutura, como neste caso - as palafitas, localizadas nos estuários, margens de rios e manguezais, estando expostas a diversos níveis de riscos. Em 1991, nos Estados Unidos da América (EUA), foi realizado a I Cúpula Nacional de Lideranças Ambientais de Povos de Cor, um grande evento realizado em uma das maiores potências nacionais, agregando o movimento ambientalista ao movimento negro, fortalecendo a luta contra a desigualdade ambiental nos EUA (ACSELRAD, 2004). O autor aponta ainda que a importância da unificação das pautas resultou em movimentos com lemas que promoveram a luta contra injustiças ambientais, como "poluição tóxica pra ninguém", ressaltando o compromisso em não realocar as populações menos favorecidas para os locais de poluição.

Já no Brasil, como forma de promover o debate, foi realizado na Universidade Federal Fluminense, o Colóquio Internacional sobre Justiça Ambiental, Trabalho e Cidadania, em setembro de 2001, sendo um marco, devido a sua importância e urgência presente nessa temática (HERCULANO, 2002). Como produto desse colóquio foi criada a Rede Brasileira de Justiça Ambiental (RBJA), ressaltando a necessidade de promover debates, ultrapassando as questões apenas de gênero, que comumente são tomadas como exclusivas na problemática (CARTIER et al., 2009). 
O racismo surge a partir da exclusão de pessoas pela tonalidade da pele, vestígio do período da escravatura, onde os negros eram apenas objetos passíveis de trocas e vendas. Dessa forma, as diversas esferas do racismo contribuem para o racismo ambiental, sendo a prevalência do homem branco, conseguindo ambientes mais limpos e fora dos subúrbios das cidades (PULIDO, 2000). A cor da pele influência na discriminação e exposição a riscos ambientais, como contato direto com ambientes poluídos e degradados. Herculano (2008) comenta que o racismo ambiental não pode ser ligado apenas a questão de raça, mas todas as ações que apresentem uma intenção racista. A autora aponta ainda que o racismo ambiental:

Diz respeito a um tipo de desigualdade e de injustiça ambiental muito específico: o que recai sobre suas etnias, bem como sobre todo grupo de populações ditas tradicionais - ribeirinhos, extrativistas, geraizeiros, pescadores, pantaneiros, caiçaras, vazanteiros, ciganos, pomeranos, comunidades de terreiro, faxinais, quilombolas etc. - que têm se defrontado com a 'chegada do estranho', isto é, de grandes empreendimentos desenvolvimentistas - barragens, projetos de monocultura, carcinicultura, maricultura, hidrovias e rodovias - que os expelem de seus territórios e desorganizam suas culturas, seja empurrando-os para as favelas das periferias urbanas, seja forçando-os a conviver com um cotidiano de envenenamento e degradação de seus ambientes de vida (HERCULANO, 2008, p. 16).

A supressão do território a partir da especulação imobiliária, que já no seu fundamento vai beneficiar apenas uma pequena parcela da sociedade que detém o capital, refugia as populações desfavorecidas economicamente e socialmente em locais insalubres. O não reconhecimento como semelhante, impulsiona o desmembramento das sociedades, categorizando principalmente em detentores do capital e não-detentores, assim como por questões raciais, marginalizando e excluindo pessoas que na base são semelhantes. Terras baratas, com alto índice de degradação ambiental, são ocupadas por populações carentes de apoio político e/ou ações governamentais, sendo discriminadas pela sociedade (ACSELRAD, 2002).

O modelo econômico do Brasil, assim como seus planos de desenvolvimento, são a base para o surgimento de conflitos, devido ao seu caráter socialmente injusto e ambientalmente insustentável (PORTO; MILANEZ, 2009). Mesmo trazendo o discurso de que o desenvolvimento nacional apresenta uma base sustentável, ele é caracterizado como economicista, mas que vende o produto como "verde" e ecologicamente correto. A forma como o crescimento econômico vem sendo injetado traz a natureza como instrumento para saciar o ego capitalista (ESPÍNDOLA; ARRUDA, 2008). Herculano (2013) comenta que o desenvolvimento produz desigualdades, como o crescimento do Produto Interno Bruto (PIB) menor do que as dívidas do governo, aumento no número de crianças vivendo em situação de calamidade, onde $77 \%$ das famílias brasileiras vivem com no máximo um 
salário mínimo mensal, o aumento no número de favelas a partir do processo de urbanização e por fim, a elevada taxa de degradação ambiental.

O racismo ambiental cresce a partir dessa base capitalista agregada, que prega a mensuração de valor a natureza somada a base racista intrinsicamente contida na história humana, exaltado o processo de domínio do poder. Nos processos de ocupação dos grandes centros urbanos, as regiões centrais das cidades eram ocupadas por pessoas que apresentavam algum tipo de posse, e era lá onde ficavam as igrejas, bancos e prefeituras, sem a presença da natureza nos projetos urbanísticos. Os pobres ficam às margens da população rica, bem como os elementos da natureza, retratando a segregação do desenvolvimento (HERCULANO, 2000). As áreas ocupadas foram principalmente os locais de morros, manguezais e beira de rios, ditos sem importância cênica, visto que eram considerados locais sem beleza, e com baixo valor econômico.

Esses espaços passam na atualidade por uma requalificação no valor agregado, tornando-se um bem elitista em grandes empreendimentos, a partir de uma valoração financeira da natureza, configurando como apenas um artifício da sociedade capitalista (HENRIQUE, 2006). Essa reaproximação surge como marketing verde, agregando valor aos bens natural com megaempreendimentos, negando o acesso da população que vive nas periferias, ressaltando apenas como de qualidade o verde encontrado nesses espaços.

A exclusão e marginalização das áreas negligenciadas pelos empreendimentos/sociedade agrava os casos de racismo ambiental, causando mais desinteresse. Pacheco (2008) comenta sobre esse cenário de desenvolvimento:

\footnotetext{
O modelo de desenvolvimento hegemônico no mundo atual cada vez mais trata a maioria da humanidade como objetos: uns, a serem usados a serviço do lucro; outros, considerados supérfluos, a serem sumariamente descartados. Ou somem das estatísticas a partir de causas "naturais" decorrentes da desnutrição ou de doenças causadas pela miséria absoluta, ou são expulsos de seus lares para que megaprojetos se estabeleçam, ocupando e arrasando o território para "implantar empregos, progresso, desenvolvimento sustentável e cidadania". Como apregoam, aliás, os belos sites dos conglomerados - nacionais e internacionais responsáveis por essa situação (PACHECO, 2008, p.1).
}

O modelo hegemônico do desenvolvimento aumenta os casos de racismo ambiental, excluindo os menos favorecidos a partir de esferas construídas pela sociedade, embebidos nos diálogos preconceituosos da grande mídia, assim como a exclusão gerada pelo capital (PACHECO, 2008). Exemplos dessas ameaças estão a supressão da terra nas comunidades tradicionais do Cerrado a partir da expansão da monocultura (MELO, 2017), e a carência na disponibilidade de água e saneamento básico em comunidades artesanais situada no alto trecho do rio Pajeú, no semiárido do Estado de Pernambuco (MENDONÇA et al., 2012). 
Os casos de racismo ambiental são divulgados através de denúncias em esfera legal e através de mídias sociais e de comunicação, quando são divulgadas através de reportagens investigativas. Seguindo o mapa proposto por Pacheco (2010), os casos de denúncia estão concentrados na zona costeira, ligados às questões de posse da terra, envolvendo locais de pertencimento e origens, como no caso dos povos indígenas, agricultores familiares, quilombolas, pescadores artesanais e ribeirinhos. O autor ainda aponta que os casos de conflitos estão ligados a negação dos direitos de terra, sendo pressionados principalmente pela monocultura, mineração, garimpo, siderurgia, madeireiras, barragens hidrelétricas, indústrias químicas e de petróleo de gás, pesca industrial e carcinicultura intensiva, pecuária, hidrovias, rodovias, gasodutos e os agrotóxicos. A negação do direito à terra (territórios) está interligada a falta de políticas públicas que atendam essas populações, assim como a negligência dos órgãos municipais, estaduais e federais para/com os problemas locais.

\section{A exclusão: caso das comunidades artesanais pesqueiras}

A pesca artesanal é uma atividade realizada inicialmente por comunidades indígenas, seguidas por quilombolas, jangadeiros, entre outras comunidades que retiram total/parte do seu sustendo dos rios e mares (DIEGUES, 2000), além dos manguezais e gamboas. A prática pesqueira começou a ser introduzida como classe de trabalho, em conjunto com a agricultura, como as caiçaras (SILVA, 1993). No entanto, atualmente, pode ser classificada como uma forma não assalariada e não capitalista de realizar uma atividade, onde seus costumes e práticas são passados através da oralidade, dessa forma, os filhos adquirem o legado da pesca pelos pais, adaptando-os quando necessário.

A práxis da pesca constrói os sítios simbólicos de pertencimento, que corresponde aos valores passados de geração para geração, experiências e contextos simbólicos espirituais que constroem o ser (HASSAN, 2006). Dessa forma, o envolvimento do pescador para/com o meio ambiente não constrói toda a sua relação, sendo expandido para as inter-relações que existem, como a venda do pescado, o contato social e seu próprio entendimento de espaço (RODRIGUES et al., 2017). A urbanização das cidades, assim como o próprio crescimento das cidades satélites e regiões metropolitanas, acarreta no pressionamento dos territórios pesqueiros, ameaçando seus costumes, ridicularizando suas tradições e marginalizando seus povos. Pacheco (2008, n.p.) traz uma reflexão importante para contextualizar quais ameaças estão presentes contra essas comunidades:

Para seus ocupantes originais - povos indígenas, remanescentes de quilombos, agricultores familiares, ribeirinhos, pescadores artesanais, caiçaras, marisqueiras e 
outros representantes de populações tradicionais - resta alguma forma de exílio. Do confinamento em assentamentos ou em reservas cada vez menores, sem condições para garantir suas tradições culturais e sequer a subsistência, ao desterro e à migração para os centros urbanos, onde dificilmente conseguirão conquistar algum espaço para viver com dignidade. Na maioria dos casos, acabarão nas zonas de risco das favelas, dos subúrbios ou do entorno de fábricas, poluídos pelos lixões e pelos resíduos tóxicos.

A exclusão e repressão das comunidades pesqueiras em pequenos núcleos as margens das cidades facilita o seu isolamento, ocupando locais com péssimas condições de moradia, desmembrando da própria dinâmica da cidade. Ora, inicialmente era comum viver às margens dos rios, apresentando uma inter-relação orgânica e holística com a natureza, mas o que difere para as condições atuais é que devido a marginalização e exclusão dessas áreas, suas condições naturais estão totalmente modificadas, apresentando elevado índice de poluição. Partindo dessa reflexão, atualmente as encostas de rios e manguezais não provêm condições mínimas necessárias para moradia, devido, principalmente, à falta de saneamento básico (MADRUGA, 2002).

Como exemplo de estudo de caso do racismo ambiental, tem-se a comunidade da Ilha de Deus na cidade do Recife, Pernambuco. O local é um exemplo de resistência em área urbana, lutando diariamente contra o racismo ambiental afetando famílias de pescadores. Além do reconhecimento da área e coletas de dados in loco, teve-se participação ativa na Audiência Pública do Parque dos Manguezais, local onde está situada a comunidade da Ilha de Deus, ocorrida no dia 26 de outubro de 2017 no Plenário da Câmara Municipal dos Vereadores de Recife e seus desdobramentos com a Participação do Ministério Público de Pernambuco (MPPE), abordando o tema no MPPE Dialoga, em 8 de novembro de 2017.

Para o desenvolvimento e vivência da pesquisa, foram realizadas seis visitas a Ilha de Deus, entre 2016 e 2017, com o objetivo de realizar observação direta (STEBINS, 1987) e observação participante (GIL, 2008) com os pescadores, possibilitando uma maior integração entre o pesquisador e a comunidade estudada. Conhecer a dinâmica de vida, da pesca, das interações e inter-relações possibilita que a própria comunidade receba e aceite a pesquisa, construindo uma relação de confiabilidade.

\section{Ilha de Deus, Recife, Pernambuco}

A comunidade da Ilha de Deus (Figura 1) está localizada na cidade do Recife, banhada por três importantes rios, sendo o Beberibe, Tejipió e Jordão, na qual os moradores vivem basicamente da pesca de diferentes recursos faunísticos, como peixes diversos (e.g., carapeba, tainha, saúna, curimã, pescada, xareu, mororó, camurim e boca mole), camarão, sururu e marisco. Segundo dados 
da Secretaria de Planejamento e Gestão de Pernambuco (SEPLAG, 2007), a Ilha de Deus consta com 334 famílias e aproximadamente 1.150 habitantes, assim como 317 residências. O nome da comunidade se deu devido à dificuldade que os primeiros moradores tinham para chegar na ilha, sendo chamada de "Ilha sem Deus", mas que com o decorrer do processo de urbanização e com a grande distribuição dos produtos pescados, os próprios moradores trocaram o nome para Ilha de Deus (RABELO, 2010).
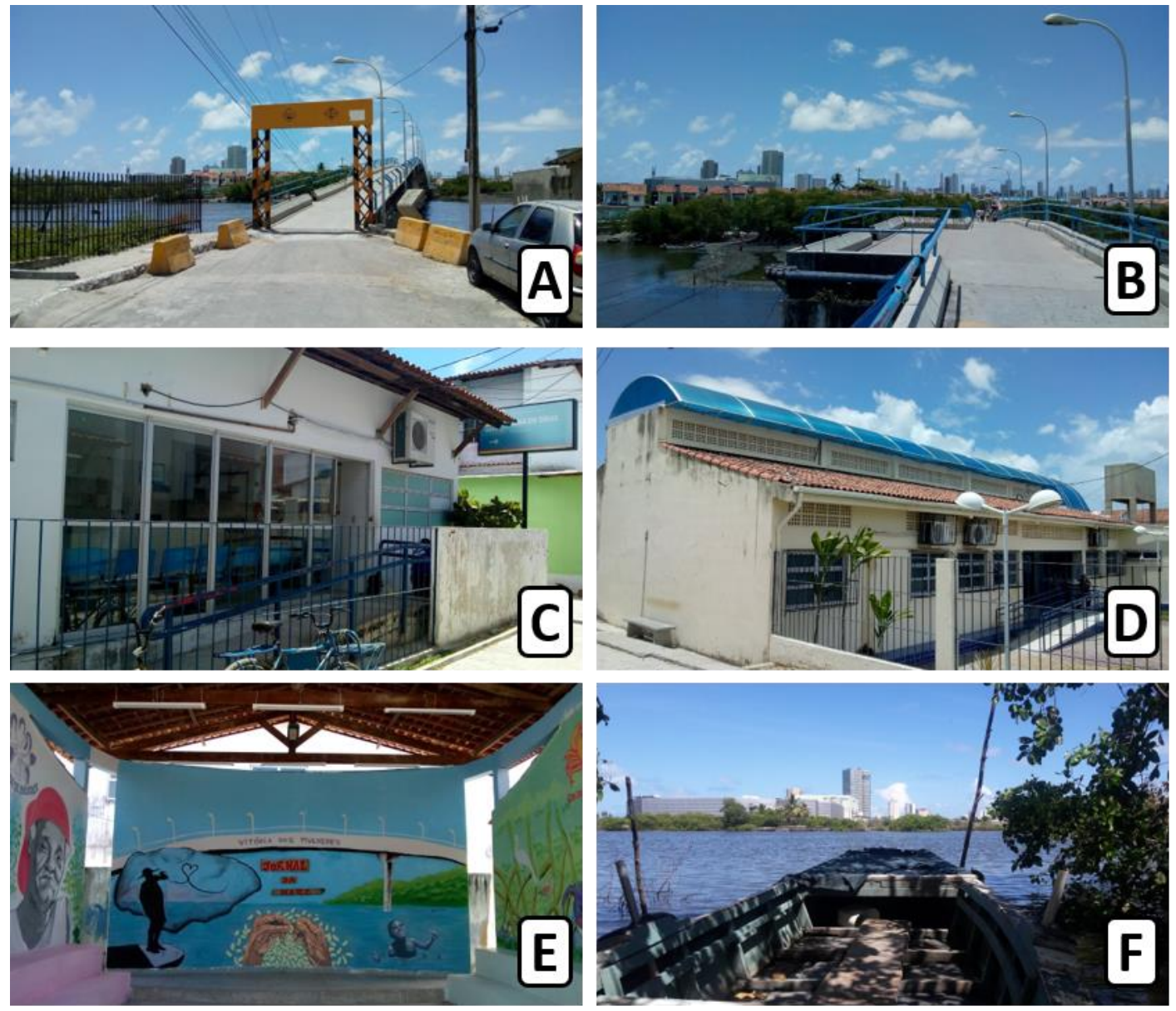

FIGURA 1: CARACTERIZAÇÃO VISUAL DA ILHA DE DEUS. A: ENTRADA DA ILHA DE DEUS. B: VISTA SOBRE A PONTE VITÓRIA DAS MULHERES. C: UNIDADE DE SAÚDE DA FAMÍLIA. D: ESCOLA ESTADUAL. E. SEDE DA AÇÃO COMUNITÁRIA CARANGUEJO UÇÁ. F: VISTA PARA O SHOPPING RIO MAR. FONTE: Rubens Trajano, 2018.

A Ilha está situada em uma ZEIS (Zona Especial de Interesse Social), que configuram áreas com problemas relacionados ao uso e ocupação do solo, servindo como base para a construção de planos urbanísticos que possam intermediar os conflitos, sendo instituída a partir da Lei 9.785/99 que regulamenta a Lei de Parcelamento do Solo (6.766/79). O local também faz parte do Parque Natural Municipal Josué de Castro, conhecido como Parque dos Manguezais, sendo uma Área Protegida de domínio da Marinha do Brasil, sendo a fonte de diversos conflitos com a comunidade pesqueira. 
A Bacia do Pina tem relevante importância histórica e social, no qual esse foi o estuário utilizado pelos holandeses para adentrar na Cidade do Recife, no início do século XVII. A ocupação da Ilha de Deus foi inicialmente configurada pela utilização das áreas de mangue para a construção de viveiros de peixes, que posteriormente foi utilizada para o cultivo de camarão, aplicando técnicas artesanais no seu manejo a quase 50 anos. Além dos viveiros, uma característica marcante eram as palafitas, comum em comunidades pesqueiras, mas que a partir do Plano de Ação Integrada da Cidade do Recife, passou por uma requalificação urbanística, com a construção de moradias, saneamento e áreas de lazer no próprio local. A origem do pescador, assim como seus costumes e práxis foi respeitada, visto que foi garantida uma melhoria na sua qualidade de vida sem desqualificar da sua identidade com uma mudança brusca no local de moradia.

A cidade enxerga a ilha como uma "comunidade única periférica e carente", segundo o relato de um pescador, não contemplando toda a sua importância quanto resistência e quanto a distribuição dos recursos pesqueiros. O sentimento é de indignação quanto a exclusão da comunidade, visto que Recife é uma cidade tradicional pesqueira (parafraseando um pescador), mas que sofre com a verticalização das moradias e da pressão ao acúmulo de capital "quem tem poder vai pra verticalização, quem não tem fica nas casinhas pintadinhas, isso é demarcação de poder". Vasconcelos (2005) traz que a exclusão de comunidades (principalmente as tradicionais pesqueiras) é um resultado do sistema capitalista, onde são desqualificados para dar vez as construções de luxo, tratando apenas como periféricos. A falta de saneamento, coleta do lixo, segurança pública, invisibilidade das atividades de pesca por pescadoras atribuem o retrato falado de locais perigosos ou de tráfico de drogas.

O racismo ambiental insurge com a negligência não apenas do pescador, mas de toda a arte da pesca artesanal, excluindo e não reconhecendo quem trabalha na maré e supervalorizando apenas o seu produto (pescado), amplamente vendido como uma iguaria nos mercados, bares e restaurantes da cidade do Recife. Segundo um pescador da Ilha de Deus "As pessoas comem os nossos produtos, mas não sabem nem de onde veio", ressaltando o desmembramento entre o produto que é comercializado com a comunidade pesqueira. Seguindo esse pensamento, a própria poluição gerada nos grandes centros urbanos, que é canalizada para os estuários, acaba servindo de alimento para os recursos pesqueiros que são coletados e vendidos na Cidade do Recife. A sensação de exclusão não afeta diretamente as atividades da comunidade, ao contrário, os pescadores e pescadoras se sentem felizes com o seu trabalho na maré, trazendo uma relação de respeito e harmonia com a natureza, segundo moradores. 
A falta de condições de trabalho para quem vive da pesca artesanal é algo ainda marcante, onde o processo de beneficiamento do pescado, principalmente o sururu (Mytella charruana, D’ORBIGNY, 1842), é realizado a céu aberto, nas ruas da comunidade, descartando os resíduos no próprio manguezal. Dados fornecidos pelos pescadores é que são beneficiados 1 tonelada/dia de sururu em alta temporada na Ilha de Deus. Os pescadores e pescadoras são diariamente marginalizados, sendo privados de políticas públicas assistencialistas destinada a esse público, principalmente voltadas para a saúde, visto elevado esforço físico e repetitivo que a atividade pesqueira induz, necessitam de tratamento ergométricos. As Lesões por Esforço Repetitivo (LER) é comum principalmente para quem realiza a pesca de bivalves, necessitando ações que visem a redução dos danos devido ao LER (PENA, FREITAS e CARDIM, 2011). Como a atividade artesanal pesqueira não segue os padrões do mercado formal, o Sistema único de Saúde (SUS) não garante inclusão desses grupos (PENA, MARTINS e REGO, 2013).

A especulação imobiliária é um dos principais fatores que afetam diretamente os moradores da ilha, devido a supressão de áreas de mangue por grandes empreendimentos como no caso do Shopping Rio Mar, o projeto urbanístico Via Mangue e o condomínio de luxo Le Parc, situados entre os bairros do Pina e Boa Viagem. O cais José Estelita, situado na bacia do Pina, vestígio histórico da arquitetura holandesa no Recife, por pouco não foi derrubado para a execução do projeto intitulado "Novo Recife" que visava a construção de torres de apartamentos de luxo, mas que a partir de ações populares demonstraram que o local poderia ser ocupado por todo o Recife (NETO, 2015). O movimento conhecido como Ocupe Estelita, inspirado no movimento Occupy Wall Street, com representante de diversas esferas conseguiu barrar a construção das torres, sendo um dos argumentos a questão dos elevados impactos ambientais que seriam resultantes desse empreendimento (LYRA, 2015; NETO, 2015; TAVOLARI, 2016).

A pressão exercida pela urbanização das áreas naturais pode influenciar na condição ambiental, como no estudo realizado por Cavalcanti-Silva et al. (2017) na Região Metropolitana do Recife, no qual observou-se uma drástica redução na vegetação local. Dessa forma, a própria permanência da comunidade da Ilha de Deus agrega a proteção de manguezal local, que corresponde a grande parcela de manguezal presente ainda em bom estado de conservação na Cidade do Recife.

Nos momentos de luta contra a retirada das áreas de manguezal pelos empreendimentos, os moradores se juntam, trazendo seus conhecimentos práticos, obtido através da oralidade de antepassados e da práxis da comunidade, demonstrando como essa retirada pode influenciar nos recursos pesqueiros e/ou na qualidade de vida dos recifenses, visto que essa é uma das poucas áreas de mangue da cidade. Um exemplo de luta em conjunto foi para a criação da Reserva Extrativista 
Acaú-Goiana, situada entre o litoral Sul da Paraíba e litoral Norte de Pernambuco, onde as mobilizações foram organizadas pelas mulheres marisqueiras, tomando frente dos espaços de decisão (FADIGAS; GARCIA, 2010; LIMA; SELVA; RODRIGUES, 2016).

A resistência de uma comunidade pesqueira, com costumes e práticas artesanais, em meio de um grande centro urbano é mais do que uma conquista, sendo um símbolo de identidade e persistência dos pescadores e pescadoras. A beleza cênica proveniente da ilha está na vegetação de mangue, nas interações sociais, na pesca, no estuário e no sorriso dos moradores, contribuindo e ressaltando a importância da preservação dessa comunidade "quem trabalha sujo, trabalha com grandes riquezas".

Não é geograficamente distante que se encontram exemplos de comunidades pesqueiras que vivem diariamente lutando pelo direito de realizar a pesca artesanal, assim como, pela visibilidade dos pescadores. Na praia de Suape, localizada na Cidade do Cabo de Santo Agostinho na Região Metropolitana do Recife, existem comunidades pesqueiras de vivem em complexos embates com o complexo industrial instalado no local. Ramalho (2010) traz Suape como exemplo de resistência em comunidade pesqueira, onde as tradições tentam ser mantidas mesmo com elevada pressão econômica capitalista proveniente do complexo industrial. $\mathrm{O}$ autor traz ainda que os pescadores apresentam um sentimento de prazer com a atividade pesqueira, ressaltando a relação humanizada e comunitária.

\section{Considerações Finais}

O racismo ambiental surge da negligência dos direitos básicos e da exclusão dos pescadores artesanais, onde sua resistência em centros urbanos representa um desafio, sendo necessário a quebra do paradigma que exclui as populações ribeirinhas, trazendo a concepção de igualdade e respeito. $\mathrm{O}$ reconhecimento tem início com o repasse do valor obtido na venda final do produto para o pescador, agregando valor ao produtor de base e não aos atravessadores e/ou grandes empreendimentos.

A comunidade da Ilha de Deus é conhecida por estar situada em um dos poucos fragmentos de manguezal urbano, contém uma beleza cênica única e responsável pela distribuição dos principais recursos pesqueiros da Cidade do Recife. Os pescadores são exemplos de resistência, construindo uma relação de trabalho que foge dos padrões capitalistas, apresentando uma relação harmônica com a natureza.

\section{Referências}


ACSELRAD, H. Justiça ambiental e construção social do risco. Desenvolvimento e Meio ambiente, n.5, p.49-60, 2002.

ACSELRAD, H. Meio ambiente e justiça - estratégias argumentativas e ação coletiva. In: ACSElRAD, H.; HERCUlANO, S.; PÁDUA, J. A. Justiça Ambiental e Cidadania. Rio de Janeiro: Relume Dumará, p. 23-40, 2004.

BRANCO, S.M. Conflitos conceituais nos estudos sobre meio ambiente. Estudos Avançados, v.9, n.23, 1995.

BRASIL. Constituição (1988). Constituição da República Federativa do Brasil. Brasília: Supremo Tribunal Federal.

BRASIL. Lei n 6.938, de 31 de agosto de 1981. Dispõe sobre a Política Nacional do Meio Ambiente, seus fins e mecanismos de formulação e aplicação, e dá outras providências. Disponível em: <http://www.planalto.gov.br/ccivil_03/leis/L6938.htm>. Acesso em: 15 nov. 2017.

BRASIL. Lei $\mathbf{n}^{\circ}$ 9.433, de 8 de janeiro de 1997. Institui a Política Nacional de Recursos Hídricos, cria o Sistema Nacional de Gerenciamento de Recursos Hídricos, regulamenta o inciso XIX do art. 21 da Constituição Federal, e altera o art. $1^{\circ}$ da Lei $n^{\circ}$ 8.001, de 13 de março de 1990, que modificou a Lei $\mathrm{n}^{\mathrm{o}}$ 7.990, de 28 de dezembro de 1989. Disponível em: <http://www.planalto.gov.br/ccivil_03/leis/L9433.htm>. Acesso em:15 nov. 2017.

BRASIL. Lei $\mathbf{n}^{\mathbf{0}}$ 9.605, de 12 de fevereiro de 1998. Dispõe sobre as sanções penais e administrativas derivadas de condutas e atividades lesivas ao meio ambiente, e dá outras providências. Disponível em: <http://www.planalto.gov.br/ccivil_03/leis/L9605.htm>. Acesso em: 15 nov. 2017.

BRASIL. Lei n 9.795, de 27 de abril de 1999. Dispõe sobre a educação ambiental, institui a Política Nacional de Educação Ambiental e dá outras providências. Disponível em: <http://www.planalto.gov.br/ccivil_03/leis/L9795.htm>. Acesso em: 15 nov. 2017.

BRASIL. Lei $\mathbf{n}^{\mathbf{0}}$ 9.985, de julho de 2000. Regulamenta o art. 225, § $1^{\circ}$, incisos I, II, III e VII da Constituição Federal, institui o Sistema Nacional de Unidades de Conservação da Natureza e dá outras providências. Disponível em: <http://www.planalto.gov.br/ccivil_03/leis/L9985.htm>. Acesso em: 15 nov. 2017.

BRASIL. Decreto $\mathbf{n}^{\circ}$ 6.848, de maio de 2009. Altera e acrescenta dispositivos ao Decreto no 4.340 , de 22 de agosto de 2002, para regulamentar a compensação ambiental. Disponível em: <http://www.planalto.gov.br/ccivil_03/_ato2007-2010/2009/decreto/d6848.htm>. Acesso em: 15 nov. 2017.

CARTIER, R.; BARCELLOS, C.; HUBNER, C.; PORTO, M.F. Vulnerabilidade social e risco ambiental: uma abordagem metodológica para avaliação de injustiça ambiental. Caderno de Saúde Pública, Rio de Janeiro, v.25, n.12, p.2695-2704, 2009.

CALVALCANTI-SILVA, E.R.A.; SANTANA, S.H.C.; MELO, J.G.S.; MENDES, S.M.; GALVÍNCIO, J.D. A transformação da natureza e as potencialidades do monitoramento ambiental na Lagoa Urbana Olho d'água - PE: os desafios da complexa relação entre desenvolvimento urbano e a conservação de ambientes naturais. Guaju, v.3, n.2, p.32-64, 2017. 
CIDREIRA-NETO, I.R.G.; RODRIGUES, G.G. Relação homem-natureza e os limites para o desenvolvimento sustentável. Recife, v.6, n.2, p.142-156, 2017.

DIEGUES, A.C. Os saberes tradicionais e a biodiversidade do Brasil. São Paulo: MMA/COBIO/NUPAUB/USP, 2000.

DUARTE, R. Marx e a natureza em O Capital. Edições Loyola, v.4, 1986.

ESPÍNDOLA, M.A.J.; ARRUDA, D.O. Desenvolvimento sustentável no modo de produção capitalista. Revista Visões, v.1, n.4, 2008.

FADIGAS, A.B.M.; GARCIA, L.G. Uma análise do processo participativo para a conservação do ambiente na criação da Reserva Extrativista Acaú-Goiana. Sociedade \& Natureza, v.22, n.3, p.651$576,2010$.

GIL, A.C. Métodos e Técnicas de Pesquisa Social. São Paulo: Atlas, 2008.

GROSTEIN, M.D. Metrópole e expansão urbana: a persistência de processos “insustentáveis”. São Paulo em Perspectiva, v.15, n.1, p.13-19, 2001.

HASSAN, Z. Nova economia das iniciativas locais: uma introdução ao pensamento Pós-global. Tradução Michel Thiollent. Rio de Janeiro: Consulado Geral da França, 2006.

HENRIQUE, W. A cidade e a natureza: a apropriação, a valorização e a sofisticação da natureza nos empreendimentos imobiliários de alto padrão em São Paulo. GEOUSP: Espaço e tempo, São Paulo, n.20, p.65-77, 2006.

HERCULANO, S. Ambiente urbano, pobreza e desenvolvimento sustentável. Revista Nação Brasil, Rio de Janeiro, v.122, n.4, p.38-40, 2000.

HERCULANO, S. Resenhando o debate sobre justiça ambiental: produção teórica, breve acervode casos e criação da rede brasileira de justiça ambiental. Desenvolvimento e Meio ambiente, n.5, p.143-149, 2002.

HERCULANO, S. O clamor por justiça ambiental e contra o racismo ambiental. InterfacEHS: Revista de Gestão Integrada em Saúde do Trabalho e Meio Ambiente, São Paulo, v.3, n.1, 2008.

HERCULANO, S. Desenvolvimento econômico, desigualdades sociais e ambiente urbano deteriorado: o que fazer?. Revista VITAS: Visões Transdisciplinares sobre Ambiente e Sociedade, n.7, 2013.

JACOBI, P. Dilemas socioambientais na gestão metropolitana: do risco à busca da sustentabilidade urbana. Revista de Ciências Sociais, n.25, p.115-135, 2006.

LIMA, M.E.A.; SELVA, V.S.F.; RODRIGUES, G.G. Gestão participativa nas reservas extrativistas: a atuação do Instituto Chico Mendes da Biodiversidade. Revista Brasileira de Geografia Física, v.9, n.4, p.1072-1087, 2016.

LYRA, C. \#OCUPE ESTELITA: a resistência cultural pelo direito à cidade. Revista Políticas Públicas \& Cidades, v.3, n.3, p.93-107, 2015. 
MADRUGA, A. Entre os limites naturais do espaço urbano e da marginalização, as condições de vida das comunidades ribeirinhas. Caderno do Logepa. João Pessoa, v.1, n.1, p.11-22, 2002.

MELO, S.W.C. Desenvolvimento rural no Cerrado, desenvolvimento e envolvimento das famílias agroextrativistas. Guaju, Matinhos, v.3, n.1, p.111-131, 2017.

MENDONÇA, Z.C.L.; CANDEIAS, A.L.B.; SELVA, V.F.; SILVA, M.M.; RODRIGUES, G.G.; SANTOS, S.M. Aspectos sanitários e de uso da água em pequenas comunidades rurais do Semiárido Pernambucano. Revista Brasileira de Geografia Física. Recife, v.5, p.1191-1202, 2012.

NETO, L.P.F. Impacto à efetivação econômica e sociais da população tradicional da bacia do Pina. Núcleo de Estudos e Atuação em Relações Internacionais, v.1, n.2, p.28-48, 2015.

PACHECO, T. Racismo ambiental: expropriação do território e negação da cidadania. Série Textos Água e Ambiente, v.2, p.11-23, 2008.

PACHECO, T. Terra e território â luz do mapa da injustiça ambiental e saúde no Brasil. Tempo e Presença, v.21, 2010.

PECCATIELLO, A.F.O. Políticas públicas ambientais no Brasil: da administração dos recursos naturais (1930) à criação do Sistema Nacional de Unidade de Conservação (2000). Desenvolvimento e Meio ambiente, n.24, p.71-82, 2011.

PENA, P.G.L.; FREITAS, M.C.S.; CARDIM, A. Trabalho artesanal, cadências infernais e lesões por esforços repetitivos: estudo de caso em uma comunidade de marisqueiras na Ilha da Maré, Bahia. Ciência \& Saúde Coletiva, v.18, n.8, p.3383-3392, 2011.

PENA, P.G.L.; MARTINS, V.; REGO, R. Por uma política para a saúde do trabalhador não assalariado: o caso dos pescadores artesanais e das marisqueiras. Revista Brasileira de Saúde Ocupacional, v.38, n.127, p.57-68, 2013.

PORTO, M.F.; MILANEZ, B. Eixos de desenvolvimento econômico e geração de conflitos socioambientais no Brasil: desafios para a sustentabilidade e a justiça ambiental. Ciência \& Saúde Coletiva, v.14, n.6, p.1983-1994, 2009.

PULIDO, L. Rethinking Environmental Racism: White privilegie and urban development in Southern California. Annals of the Association of American Geographers, v.30, n.1, p.12-40, 2000.

RABELO, J.B. Habitação e sustentabilidade em áreas de fragilidade ambiental. Periódico Eletrônico Fórum Ambiental da Alta Paulista, v.6, n.5, p.323-337, 2010.

RAMALHO, C.W.N. Estética marítima pesqueira: perfeição, resistência e humanização do mar. Revista Ambiente \& Sociedade, v.13, n.1, p.95-110, 2010.

RODRIGUES, G.G.; SOUZA, A.E.V.N.; LIMA, M.E.A.; NETO, I.R.G.C.; LEITE, J.K.S.; NASCIMENTO, D.M.; HARDER, E.; FREITAS, A.E.C. Território, paisagens e identidades culturais em uma Reserva Extrativista Marinha do Nordeste do Brasileiro. Revista de Movimentos Sociais e Dinâmicas Espaciais. Recife, v.6, n.1, p.253-242, 2017. 
SEPLAG - Secretaria de Planejamento e Gestão do Estado de Pernambuco. Plano de Ação Integrada de Investimento para a ZEIS Ilha de Deus. Recife, 2007.

SILVA, L.G.S. Caiçaras e jangadeiros: cultura marítima e modernização no Brasil. São Paulo: CEMAS, 1993.

SILVA, L.E.; ALBUQUERQUE, U.P.; AMARAL, W. Uso sustentável da biodiversidade e conservação de recursos naturais. Guaju: Revista Brasileira de Desenvolvimento Territorial Sustentável. Matinhos, v.3, n.1, p.2-10, 2017.

STEBBINS, R.A. Fitting in: The Researcher as leaner and participant. Quality \& Quantity. V.21, n.1, p.103-108, 1987.

TAVOLARI, B. Direito à cidade: uma trajetória conceitual. Novos estudos, n.104, p.92, 2016.

VASCONCELOS, D.A.L. Turistificação do espaço e exclusão social: a revitalização do bairro de Jaraguá, Maceió - AL, Brasil. Turismo em Análise, v.16, n.1, p.47-67, 2005.

WAINER, A.H. Legislação Ambiental Brasileira: evolução histórica do direito ambiental. Revista de Informação Legislativa. v.30, n.118, p.191-206, 1993.

Artigo recebido em 15/03/2018. Aceito para publicação em 15/09/2018. 